\title{
A girl and her chew: one woman's story of spit tobacco use
}

I had my first chew just before my 17 th birthday. I remember it vividly. About to embark on a 21-day backpacking trip to Wyoming, a friend warned me that my smoking habit might make breathing and hiking difficult at high altitudes. He helpfully suggested that I try spit tobacco and even offered to teach me. Years later he would still boast about teaching a girl to chew.

$\mathrm{He}$ initiated me to the pleasures of chewing tobacco one night before we left for the trip. I remember learning to pack down the chew in the tin, snapping my wrist like my friend did, and I remember the sickly, minty smell. I had been a smoker for over three years at that point. Nicotine was not new to me, until my first dip. The buzz I got was stronger than one from any other substance I had tried at that point. My head spun, my heart raced, and an incredible surge swept through my body. Nauseous and dizzy, I had to sit down immediately. So this was chew, I thought. I didn't get sick, and it didn't even hurt my mouth. After a few more dips, however, I came to relish the biting sting that was the chew, tearing up my gums.

Instead of stocking up on cigarettes for the journey west, I split a "log" of chew with my friend (a $\log$ is essentially a carton of spit tobacco.) By the time I returned home, I was chewing all day and every day. That, to me, was the great advantage of chew. I could do it anywhere, anytime: in theaters, on the bus to school, in my bedroom at home (with no telltale tobacco smoke to alert my mother), even during some classes.

The tough veneer that I carried around in those days was bolstered by my chew use. I felt like a biker, an outlaw, someone with whom not to mess. If I was going to be attractive, it would be on my terms, chew and all. Buying it was never a problem, largely because of the surprised clerks: "What's a nice girl like you doing with chew?" Their attitude and that of others was exactly why I continued to chew. I was a nice girl, for the most part I managed to stay out of trouble. Chew felt like the equivalent of a tattoo to me. It set me apart. An ardent feminist even then, I reveled in blowing this gender stereotype. Chew was to me what cigarettes were to women of the 19 th century. I had come a long way, baby.

I continued chewing and outdoor travel throughout college. The two went absolutely hand in hand. Like a ballplayer who cannot leave the dugout without a chew, I instinctively slipped in a dip as I slipped into the stern of a canoe. My brand of choice was Kodiak, which also happens to be the name of a large brown bear found along the coast of Alaska and British Columbia.

Chewing felt a lot more natural in the wild. No need to carry around a spitter, I could spit on the ground or wherever I pleased. Most days I would put in a dip while I brewed coffee, another after breakfast, one more after lunch, and maybe a dessert dip to end the day. Chewing became an all-day event.

What horrifies me today is that I was never alone on those wilderness excursions. I was a trail guide for young people; my charges were adolescent girls who too often thought I was the coolest thing they'd ever known. (One girl offered to trade her brand new long underwear for my ratty, torn, old ones because mine were "so cool".) I managed to keep my addiction mainly hidden by using small amounts of chew and by sitting in the stern of the canoe. Most had no idea. Those who knew were disgusted and disappointed with me. When I look back at trail photos from those days, I am dismayed to see that most of them show me smiling with a bulging lip. I had thought I was so discreet.

During the winter break in my sophomore year of college, I went to see my dentist for a checkup. He had been my only dentist since my first visit at six years of age. He asked me about college and then looked in my mouth. "Now, what's going on here, Janey?" My gums

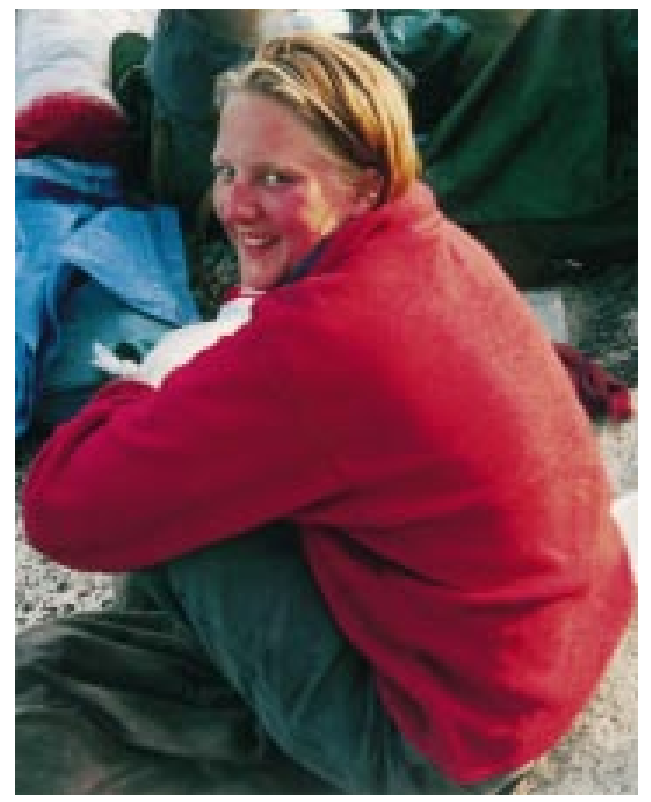

Figure 1 The author, during a trip down the Hayes River in Manitoba, Canada. 
had receded on one side; the damage was slight but irreversible. The good dentist physically recoiled when I told him the culprit. And I did, too. I knew, like most people do, that tobacco use was never advantageous. But even as a smoker (yes, I continued to smoke, too), I hadn't noticed these kinds of immediate consequences.

I didn't quit chewing then. I did quit smoking eventually. Chew proved much harder for me to stop. I still got a buzz, and I had come to love the flavor and the security of that little pinch in my mouth. But eventually, chewing no longer emboldened me, it embarrassed me. I was a health conscious, role modeling, college educated women who didn't look tough, just stupid.
I finally quit using all tobacco more than a year ago, at the age of 23. Doing research on the life and death of Bill Tuttle has profoundly affected my determination to stay quit forever. (Tuttle was the major league baseball player and anti-tobacco crusader who lost half his face and his entire life to oral cancer. My obituary of Tuttle appeared in Tobacco Control 7(4):443-444.) I still miss nicotine occasionally, and I miss that head-spinning chew buzz. But it's hard to have the snarl of a tough girl without a face, a tongue, or teeth.

JANE IMHOLTE

Association for Nonsmokers-Minnesota,

2395 University Avenue West, Suite 310,

St. Paul, Minnesota 55114, USA;

jimholte@usinternet.com
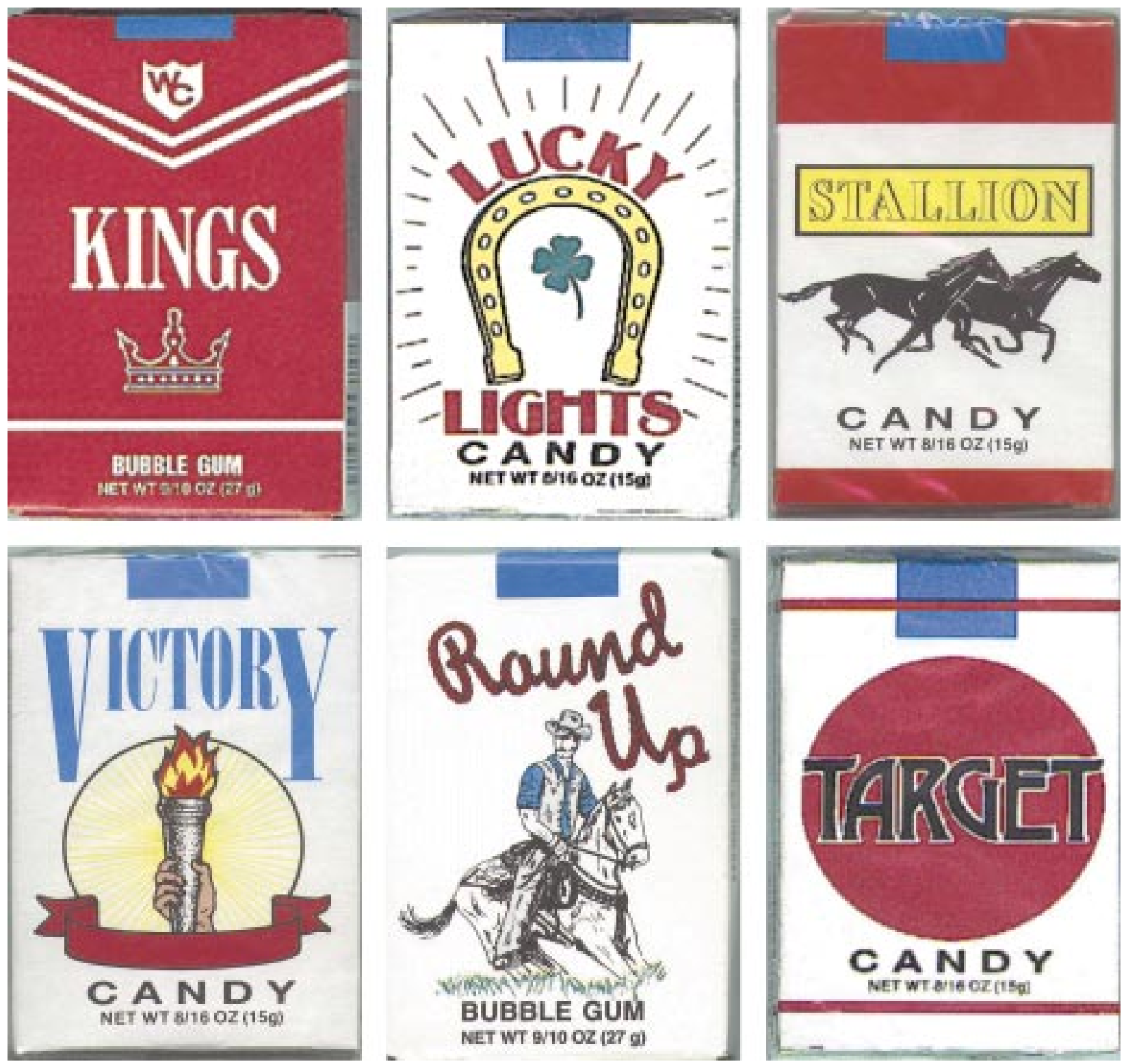

Sweet cigarette packs manufactured by World Candies Inc., Brooklyn, New York, United States. 